\title{
Causes of corruption: a survey of cross-country analyses and extended results
}

\author{
Lorenzo Pellegrini • Reyer Gerlagh
}

Received: 30 September 2005 / Accepted: 20 October 2006 / Published online: 23 February 2007 (C) Springer-Verlag 2007

\begin{abstract}
We survey and assess the empirical literature on the sources of corruption Thanks to the improved availability of data, we are able to produce an improved cross-country econometric model to test well-established and more recent hypotheses jointly. We do not find that the common law system, or a past as a British colony predicts corruption. Our results support cultural theories on the causes of corruption, and suggest that a medium-long exposure to uninterrupted democracy is associated with lower corruption levels, while political instability tends to raise corruption. Our results also suggest that the diffusion of newspapers helps to lower corruption levels.
\end{abstract}

Keywords Corruption · Ethnolinguistic fractionalization · Democracy · Political instability

JEL classification $\quad \mathrm{D} 72 \cdot \mathrm{H} 11 \cdot \mathrm{H} 50 \cdot \mathrm{K} 42 \cdot \mathrm{O} 17$

\footnotetext{
L. Pellegrini $(\varangle)$

Institute of Social Studies (ISS), Kortenaerkade 12, 2518 AX The Hague, The Netherlands

e-mail: Pellegrini@iss.nl

L. Pellegrini · R. Gerlagh

Institute for Environmental Studies (IVM), Vrije Universiteit Amsterdam, Amsterdam, The Netherlands

R. Gerlagh

University of Manchester, School of Social Sciences, Economics,

Manchester, UK
} 


\section{Introduction}

Corruption is a widespread phenomenon affecting all societies to different degrees, at different times. On the one hand, as corruption scandals have repeatedly shown, bribes are common in all countries notwithstanding differences in income levels and law systems, as they are common in democracies and in dictatorships. Recent scandals over corruption have shown that also supposedly free-from-corruption societies are affected. The ELF scandal demonstrated that corruption was rampant in the management of the French state owned enterprise. $^{1}$ The following year, a corruption charge against President Chirac could not be courted because he was shielded by immunity as the head of the state. ${ }^{2}$ Also in Germany, the CDU and former Chancellor Helmut Kohl were fined for receiving illegal campaign funding. ${ }^{3}$ Among Nordic countries (which rank always among the less corrupt in international comparisons), Swedish and Norwegian managers of state owned companies have been found to be involved in bribe-taking. ${ }^{4}$ Corruption is not rare even during humanitarian emergencies. According to Transparency International, an NGO who strives to expose corruption, relief efforts in the aftermath of the South East Asian Tsunami earthquake of 2004 were hampered by corruption. ${ }^{5}$

Still, different countries are marked by large differences to the extent of corruption. In some societies, no transaction is finalized without corruption having an effect, while in other countries it is considered an exception and rarely tolerated. Figure 1 presents corruption levels worldwide; the figure shows that corruption tends to be pervasive especially in developing countries. At the same time, numerous studies have demonstrated the pernicious effects of corrupted practices on-among other things-economic growth, investment, human development and environmental policies. The relevance of corruption for welfare levels requires the understanding of the sources of corruption (and of differences across countries) and the development of policies to address the phenomenon of corruption.

Hard evidence of corruption is intrinsically difficult to obtain, because of the secrecy surrounding illegal deals, but there are several ways to obtain proxies of the extent of corruption. One such source comes from the pool of international interviews commissioned for the Global Corruption Perception Barometer (Transparency International, 2004). From the barometer, we can see that while around $90 \%$ of Brazilians think that petty and grand corruption are 'very big problems', around $50 \%$ of Finnish interviewees think that petty corruption is 'no problem at all' and around $35 \%$ think that also grand corruption is no problem. With respect to the personal experiences of individuals with bribery,

\footnotetext{
1 On the ELF scandal see The Washington Post, Wednesday, February 9, 2000; Page A21.

2 http://archives.cnn.com/2001/WORLD/europe/10/10/chirac.court/.

3 http://www.businessweek.com/magazine/content/01_48/b3759151. htm.

4 Corruption Blackens Nordic Region's Lily-White Image, Agence France Presse, December 4, 2003.

5 http://www.transparency. org/pressreleases_archive/2005/faq_tsunami.html\#faqti1.
} 

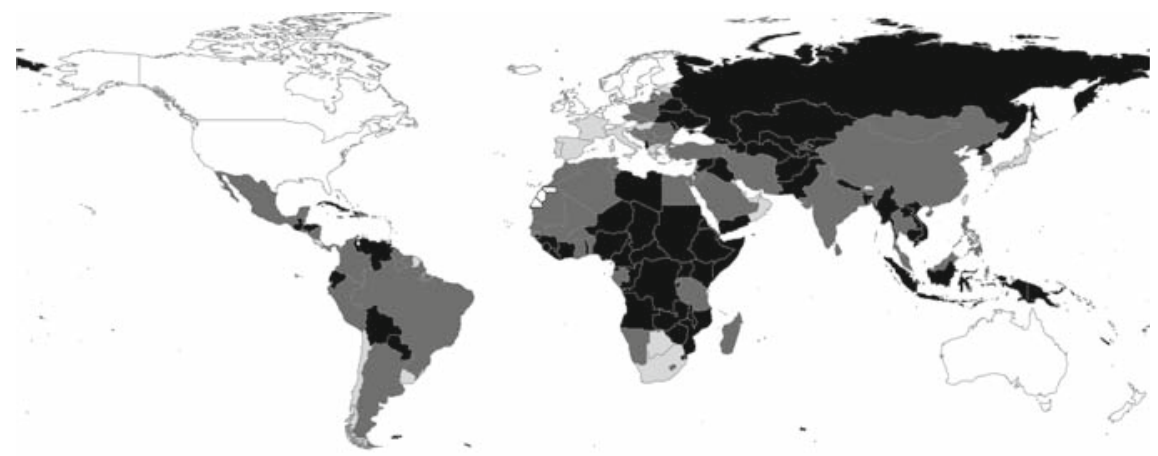

Corruption Perception

$0.0-2.5$

2.5- 5.0

5.0-7.5

7.5- $10.0 \mathrm{~N} / \mathrm{NA}$

Fig. 1 A higher score (a darker color) indicates higher corruption perception. Our elaboration on data from Kaufmann et al. (2005)

we see that more than $50 \%$ of Cameroon's interviewees admit that somebody in their household paid a bribe in the last 12 months, while among Austrian, Canadian, German and Irish interviewees only 1\% mentioned exposure to corruption for their households in the last year.

Evidence on private firms' expenditures for bribes is available from the World Business Environment Survey 2000. ${ }^{6}$ From the executives' interviews in the survey, we see for example that while more than $90 \%$ of Canadian firms declare that they did not pay any bribes in the last year, none of the Armenian and Azerbaijani firms interviewed declared so.

Once we consider the negative effects of corruption on welfare, an obvious research question arises: what is the reason for corruption to be common in some countries while other countries succeed to prevent corruption from hampering their welfare? While theoretical literature on this subject abounds, empirical studies are relatively scarce. Since several indexes of corruption perception have become available over the last few years, it is now possible to test statistically some of the ideas from the theoretical literature. To the knowledge of the authors, the most comprehensive and widely cited econometric analysis of the sources of corruption is a cross-sectional study from Treisman (2000). ${ }^{7}$ The study takes into consideration and tests empirically a wide range of theoretical explanations of corruption and finds mostly 'fixed factors' as the determinants of corruption. That is, the significant explanatory variables are all persistent over time, impossible to change in the short and medium run. The most policy-amenable variable is the 'exposition to democracy for more than 46 years'. As the sources of corruption are persistent, corruption itself will remain stable over time and can hardly be affected by policies; corrupted countries should

\footnotetext{
6 See http://info.worldbank.org/governance/wbes/.

7 This relatively recent paper has been already cited in 59 other works according to ISI Web of Science (checked on the 18th September 2005).
} 
rather learn to live with it. Treisman's study will be the point of departure of our work. ${ }^{8}$

Previous and subsequent empirical studies-mostly cross sectional-have focused more on single issues where the authors have tested a particular theory by inserting a proxy for a specific variable into multiple regressions. These studies most often produced results that confirmed the theories that were tested and, while they are valuable contributions for the identification of likely sources of corruption, they may have over-emphasized the importance of the variables analyzed because of omitted variables biases.

Several studies focused on the role of democracy as a determinant of corruption (among the most recent: Sung 2004; Chowdhury 2004 and Bohara et al. 2004), some focused on regulatory burden and economic freedom (Chafuen and Guzmàn 1999), others have focused on decentralization and federalism (e.g. Fisman and Gatti 2002; Arikan 2004), on natural resources prevalence as a source of income in the economy (Leite and Weidmann 1999), and on legal origins of a country as a determent of corruption (Glaeser and Shleifer 2002).

In our paper we will first provide a systematic overview of different theories on the causes of corruption. In this survey, presented in Sect. 2, we distinguish theories that focus on historical roots versus theories that give more attention to contemporary causes. Thereafter, we will assess the different theories and calculate our own estimates of the sources of corruption in a comprehensive econometric model, using indexes of corruption that have become available recently (Kaufmann et al. 2005) and we will cover a large sample of countries. Furthermore, we will make use of some independent variables that are improved proxies for the variables that theory would suggest. The empirical contribution of this paper is threefold. First, due to improved data availability, we can work with a larger data sample that give more power to our statistical tests compared to earlier studies. ${ }^{9}$ Second, we have a large set of independent variables available that we can test jointly so that we do not suffer from omitted variable bias, a problem of many previous and partial studies that may have overemphasized the importance of the variables under consideration. This advantage is particularly valuable as it helps us to assess the importance of long-lived versus contemporary causes of corruption, while these sources of corruption have mostly been assessed independently, so far. Thirdly, a crucial advantage over previous authors is the availability of two alternative corruption indexes, which can be used for robustness checks of the findings. Section 3 describes the data that we use for our own econometric analysis, Sect. 4 introduces and discusses the econometric estimates, and Sect. 5 concludes.

\footnotetext{
8 Lambsdorff 1999 provides a comprehensive survey of earlier empirical results.

9 Specifically, when we compare our study to Treisman's, we find that our sample is larger than 100 countries in most regressions, while Treisman's sample size is between 44 and 64 countries in the majority of regressions.
} 


\section{Theories of corruption's determinants}

Theories of corruption's determinants (and more generally of the quality of government) abound. We will take as a starting point the theories on the sources of corruption that are mentioned in Treisman (2000) and La Porta et al. (1999) as those studies are considered a benchmark in the literature and they provided a powerful battery of empirical tests. To these we will add the most recent findings of empirically backed literature in order to test and build upon their findings. The subsequent econometric estimates will follow a similar approach.

\subsection{Historical roots of corruption}

Among the theories that relate the history of countries to their present day levels of corruption, legal theories suggest that the kind of law codes that are in place in a country affect the quality of government, including the level of control of corruption. Historically motivated theories trace the effort of property owners to limit the discretionary power of the Crown as the origin of common law legal codes (Glaeser and Shleifer 2002). Furthermore, they suggest that the actions of the independent judiciary system in countries that adopted the British law code will be conductive to lower levels of corruption (for a discussion in depth, see La Porta et al. 1999).

Another theory, also based on the historical roots of corruption, is one that sees former British colonies as having a better civil service code due to the influence of the British bureaucracy. In this system, the British civil servant is focused on procedural aspects of the law, which enhances the capability of subordinates and judges to challenge hierarchies in order to enforce the law (Treisman 2000). However, as a result of the method with which colonization was imposed upon countries, this positive effect of British colonization can be questioned. Quoting Macaulay (1843/2001)' the business of a servant of the [East India] Company was simply to wring out of the natives a hundred or two hundred thousand pounds as speedily as possible, that he might return home before his constitution had suffered from the heat, to marry a peer's daughter, to buy rotten boroughs in Cornwall, and to give balls in St. James's Square'. ${ }^{10}$ If British colonizers were extracting resources, in addition to establishing legal procedures, the effect of colonization on present corruption deserves to be tested.

Another hypothesis, which has been put under scrutiny in previous literature, is that Protestant religion, being relatively less hierarchical when compared to other churches and religions (such as the Orthodox and Catholic churches and Muslims), is less prone to tolerance towards power abuses and corruption. Furthermore, the Protestant church has traditionally been apart from the state and played a role of opposition to the abuses of the government (Treisman 2000).

10 Macaulay was in India working for the Supreme Council of India and later became a member of the British Parliament. 
Thus this theory suggests that Protestant countries will be less affected by corruption.

Also pointing at long-living causes of corruption are those theories that suggest that more ethnically fractionalized countries tend to be more corrupted (Mauro 1995). One root of the link between ethnolinguistic fractionalization and corruption can be existence of alternative affiliations and obedience with respect to the state. Thus, in ethnically divided societies civil servants and politicians would exploit their positions to favor members of their own ethnic group. Another possible explanation for the effect that ethnolinguistic fractionalization would have on corruption is due to the fact that divided societies tend to under-provide public goods and this, in turn, would augment the dependency on special bounds to obtain essential services from the state.

\subsection{Contemporary causes of corruption}

Another set of theories relates the level of corruption to institutions, economic structures, and the level of development. These theories provide more of an entrance for anti-corruption policy compared to the theories based on historic variables, as there are some policy-amenable factors among the determinants of corruption. To start with, income levels may affect corruption in several ways. Richer countries can be expected to afford better institutions. Furthermore, many variables correlated with income, such as schooling levels, urbanization and access to mass media, are associated with higher development levels and they decrease the tolerance of the polity towards corruption. It may need some development to recognize corruption as a violation of the border between the public and the private sphere. Thus we expect a real income variable to be negatively correlated with corruption, where causality may run in both directions.

The rent-seeking literature emphasizes the link between corruption and possibilities for economic agents to gain access to sources of higher-than-average rents, when state intervention prevents free entry (see Rose-Ackerman 1999). In this perspective, the fight against corruption is helped with a reduction of non-generic state regulation. Thus, corruption would be associated to the size of government activities (Chafuen and Guzmàn 1999; Acemoglu and Verdier 2000). On a similar train of thought, openness to trade and increasing supply of foreign products on the domestic market enhances domestic competition, thereby reducing rents and corruption. Conversely, trade-barriers increase the opportunities for earning extra rents by gaining access to trade allowances, stimulating corruption.

Natural resources are a common source of high rents, available to those that have obtained the rights for their exploration and extraction. These rents promote activities aiming at influencing policy makers who have power on the distribution of exploitation rights, drawing away resources from other productive activities (La Porta et al. 1999). Thus natural resources abundance would be associated to higher corruption, though we cannot take this effect for granted 
since revenues from natural resources could also be used in order to produce public goods, decreasing the need to revert to bribing in order to access them.

Another strand of the literature considers the relation between social institutions and corruption, starting with democracy. A negative correlation between democracy and corruption is tautological when based on a substantial definition of democracy, since corruption favors the interests of the individual, or a minority, as opposed to the interests of the majority. Once we consider democracy from a procedural perspective (free elections and electoral competitions) the association is less straightforward. Most indexes of democracy are based on the procedural aspects of democracy, and previous empirical studies have found contrasting results. Many papers that focus on democracy and employ few control variables find contemporary democracy to decrease corruption levels (e.g. Hill 2003; Chowdhury 2004; Bohara et al. 2004), while more comprehensive studies do not find such a correlation (Treisman 2000). The experience of some Latin American countries suggests that the transition to democracy did not produce much of a dividend in terms of a reduction in corruption. A telling example is Mexico. Up to 2000, the country was ruled for seven decades by the PRI, known for its cronies and patronage system. Then, for the first time, a president was elected that was not from the PRI. This was considered a turning point for Mexican democracy, but the following years were marked by corruption scandals that affected virtually all political parties, including the ruling party (the PAN, which has gained power on its platform promoting change and a fight against corruption), ${ }^{11}$ the former ruling party PRI, the other opposition party (the PRD) $)^{12}$ and even the marginal ecologist party. ${ }^{13}$ Also in Europe, cases of corruption in long-established democracies abound; the above-mentioned high-level scandals in France are one example. As another example, Italy scores very high on all indexes of corruption, despite having been a democracy with high levels of electoral competition for six decades.

Looking at democracy, not from a procedural but from a dynamics point of view, leads us to political stability as another variable that may affect corruption levels. In politically stable administrations, bureaucrats face less chances of dismissal and have more opportunity for long-run advancement in their careers, which provides an incentive to build an open and honest reputation for a career development. On the other hand, a permanent position in power may help maintain 'patronage and corruption' reputations and relations. There are therefore two alternative and contradictory hypotheses on whether corruption is discouraged or fostered by political stability (Treisman 2000).

Apart from the duration of a job in the administration, the wages may also affect the vulnerability to corruption. Higher wages imply higher costs when

\footnotetext{
11 President Fox has been accused of using illegal funds to finance his campaign, see http://news.bbc.co.uk/hi/spanish/latin_america/newsid_2802000/2802161. stm.

12 On the tape-scandals, involving the most important aides of Lopez Obrador, see http://news.bbc. co.uk/hi/spanish/latin_america/newsid_3531000/3531475.stm.

13 On the scandal involving the young leader of the Partido Verde Ecologista, see http://www. esmas.com/noticierostelevisa/mexico/345598.html.
} 
a position in the civil service is lost, and a cost-benefit analysis suggests that higher wages thereby provide an incentive to restrain from corruption (Becker 1968; Treisman 2000).

Finally, we look at a rather different institutional variable, recently studied in both theoretical and empirical work: the extent of newspaper circulation, where the press is supposed to act as a check on those that should represent the public interest (Brunetti and Weder 2003). The hypothesis claims that corruption scandals being freely enquired and exposed by the mass medias, acts as a deterrent for bureaucrats to engage in corruption activities.

\section{Data sources on corruption}

In this section we describe our dataset and the underpinning concept of corruption. The other variables will be described below as they are introduced in the econometric analysis. The variables' sources are listed in the Appendix together with their descriptive statistics.

The assessment of corruption levels across countries is a formidable empirical challenge as corruption is difficult to define uniformly, being culturally determined, and even more difficult to measure, because illegality implies secrecy. We will use data that complies with the general definition of "abuse of power for personal gains" ${ }^{14}$ from the World Bank ${ }^{15}$ (Kaufmann et al. 2005) and Transparency International. ${ }^{16}$ The two datasets are similar in the sense that they gather existing measures on the perception of corruption, and produce an aggregate index. In this paper, we will use the data from the World Bank in the main analysis and the index from Transparency International as a robustness check.

The individual indexes aggregated in order to create the proxies of corruption (or, more precisely of corruption's perception), range from Gallup's opinion surveys - where a sample of the polity is asked how common corruption is and at what scale it operates - to surveys of company executives that estimate the share of their companies' revenues that are spent in bribes. ${ }^{17} \mathrm{On}$ the one hand, the high correlation of the aggregated indexes, originated from different sources, gives some confidence on the fact that they are correct proxies for corruption. On the other hand, it should be noted that the definition of corruption can be interpreted differently in different cultural contexts and that there can be 'emotionally driven' answers to survey: thus, while a corruption scandal is escalating, the interviewees will possibly overrate the level of corruption, just as when the economy is booming interviewees can have a more positive attitude also about the government and the civil servants. While some of these

\footnotetext{
14 For an overview of complexities and the evolution in social sciences of the definition of corruption see Williams 1999.

15 Available at http://www.worldbank.org/wbi/governance/data.html.

16 Available at http://www.icgg.org/.

17 For a full description of all the sources and of the aggregation methodology used by the World Bank, see Kaufmann et al. 2005; for sources and methodology of the Transparency International index, see Lambsdorff 2004.
} 
concerns are taken care of by the way the polls are realized and aggregated, a margin of uncertainty is inevitable (see Kaufmann et al. 2005). Furthermore, as it has been shown extensively in the empirical literature, even though these indexes may define the perception of corruption over its essence, it appears that perceptions have an impact on the economy and that the indexes have a high explanatory power when used as independent variables in econometric analyses (for a review see Jain 2001). Lastly, from the descriptive statistics of Table 2, note that the corruption index has a mean of 0 and a standard deviation of around $1 .^{18}$ Thus our results can be easily interpreted in standardized form.

\section{Empirical analysis}

In this section we provide cross-country estimates of the sources of corruption, highlighting where and why our data and results differ from previous studies. Following Treisman's (2000) methods, we will firstly test the hypotheses-already summarized in the previous section-based on the more stable variables and subsequently include variables that can change over time and that can more easily be influenced by public policies. Our preferred estimation technique is weighted least squares regressions, where the weights of the estimates are the reciprocal of the margins of errors of the corruption index for each individual observation (as estimated by Kaufmann et al. 2005). Thus, the estimates of corruption perception that are more uniform across sources are considered more reliable and get a higher weight in the regressions. ${ }^{19}$ The dataset on corruption perception is very extended and includes a number of very small countries with typical features (e.g. having an attractive investment climate) that can easily lead to selection bias in our results. ${ }^{20}$ For this reason, we omit from the empirical analysis countries that have less than 1,000,000 inhabitants.

We begin including as independent variables in our regressions a dummy variable for the common law system, a dummy for British colonies including the UK itself, ${ }^{21}$ a measure of the percentage of protestants in the population, a measure of ethnolinguistic fractionalization, and a resource abundance

\footnotetext{
18 The standard deviation is exactly equal to 1 in the complete sample, but because of missing data it changes slightly in each sample.

19 Our results hold also for ordinary least squares estimations, but as expected weighted least squares produce more 'precise' estimates (i.e. slightly higher $t$ statistics).

20 One example of the special features that very small countries have is the more limited extent of ethnoguistic fractionalization and the fact that they tend to be more open to trade (e.g. Knack and Azfar 2003). Since small countries are included in corruption surveys only when they are more interesting for investors, the over-representation of small countries with good investment climate and low corruption levels could easily introduce in the sample a spurious correlation between corruption, openness (negative) and ethnolinguistic fractionalization (positive).

21 Being a former-British colony should affect the degree of corruption because of the lasting effect British occupation has on the organization of the civil service. The UK has that same civil service organization and this is the reason for including the UK together with its former colonies in the dummy.
} 
measure based on the percentage of fuels, metals, and minerals in exports. These variables are predetermined by the history of the country or by natural characteristics and can be considered fixed over long time scales. The dependent variable is the corruption index from the World Bank for the year 2004. The results are reported in Table 1.

In regression (1), we find results that throw some doubt on many conventional findings. Specifically, while as in most previous analysis we do find a strong correlation with some of the country fixed factors, we find that neither the existence of a common law system or having been a British colony are aspects associated with a country's corruption levels. This result challenges the hypothesis that having adopted the British law system or having a past as a British colony reduces corruption at present day (e.g. Treisman 2000; Glaeser and Shleifer 2002). When we compare Treisman's work, where he found a British colonial past to be an important determinant of present levels of perceived corruption, with the model and variables used in this study, we find that our dataset is largely expanded (there are up to 107 countries in our regressions, almost double the number of countries in the largest dataset from Treisman) and that the index of corruption we are using has a lower standard error associated with it. ${ }^{22}$ We ascribe our finding to the fact that our dataset includes countries that were not included in previous studies, are former British colonies, and are also perceived to be very corrupt. ${ }^{23}$ As a British colonial past tends to overlap with the Common law system, ${ }^{24}$ collinearity is a risk in considering these highly correlated variables, and we also include them separately in the regressions. ${ }^{25}$ We still find the two variables to be individually non-significant.

In our analysis, one factor that significantly affects the level of corruption in all regressions with sufficiently large sample size is the percentage of Protestants in the population, which is negatively associated with the level of perceived corruption. This finding relates to the theories of culture and the work of those (Weber and Landes 1999 among others) that suggest that religion is a fundamental character shaping culture. The influence of the presence of Protestants over corruption is confirmed over the different specifications and is always statistically very significant. It must be noted that, from regression (2) to (9), the introduction of other independent variables more than halves the coefficient of Protestant religion prevalence. The conversion of $20 \%$ of the population from a non-protestant religion to the protestant religion (a one standard deviation

\footnotetext{
22 For a thorough comparison of the corruption perception index from Transparency International and the one from the World Bank, see Kaufmann et al. 2005.

23 Our dataset includes former British colonies such as Myanmar and Sudan, which rank among the countries where corruption is perceived to be the highest in the world. Data on these countries has only recently become available.

24 The list of countries, in our dataset, that experienced British control, but did not adopt the British legal system are: Egypt, Iraq, Jordan, Kuwait, Myanmar, Mauritius, and Oman. Countries, included in the dataset, that adopted the British legal system without being colonies are: United Arab Emirates, Liberia, Namibia, Saudi Arabia, Somalia, and Thailand.

25 We also computed the variance inflator factors, for both variables, which were well below the conventional level of 10 .
} 


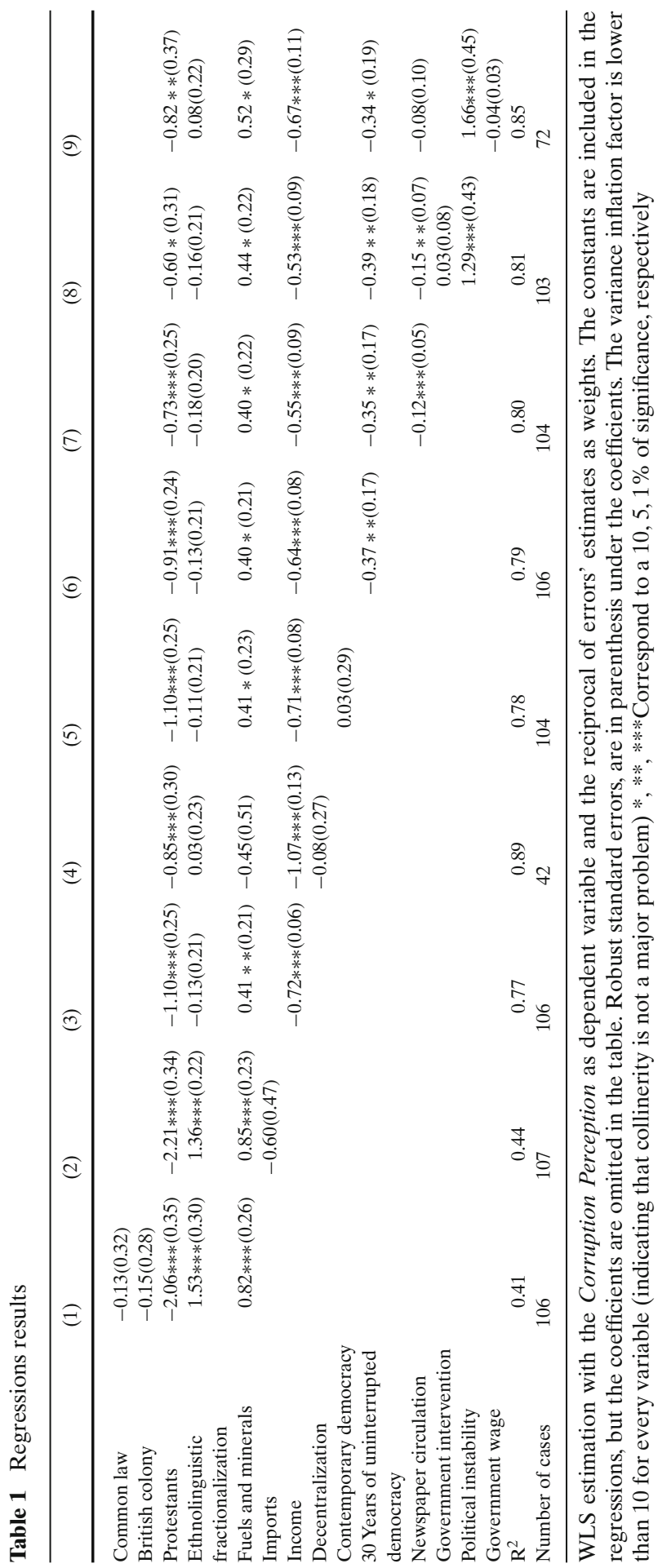


change) would be associated with a reduction in the corruption index by 0.2 points on an approximate $0-4$ scale, that is one fifth of a standard deviation.

Associating the prevalence of fuels and minerals with corruption is not a new concept. In an influential paper, Leite and Weidmann (1999) found that corruption levels are statistically associated with natural resources and provide a rent-seeking explanation. When compared to their analysis, our substantially expanded dataset still finds the same association, though the relation is not as strong as in their results. Thus, in our model, a change of $25 \%$ in the value of natural resources on exports (i.e. a one standard deviation change) would be associated with a change of 0.20 points in our corruption perception index.

In regression (2) we include, as a proxy for openness, the share of imports in GDP averaged over of a period of 10 years. We find it not to be a significant predictor of the corruption index. This result differs from Treisman who found imports over GDP to be associated with a decrease of the corruption index, but it corresponds with the results from Knack and Azfar (2003) who have disputed the link between trade intensity and corruption. The difference between results can be ascribed to the propensity of smaller datasets to be affected by selection bias. That is, earlier and less comprehensive surveys tended to include small economies only when they were of interest for international investors who are the main source of funding for the surveys. The selection thus favored small countries that were open and not very corrupt.

The inclusion of income as an independent variable in Regression (3), causes some major changes in all coefficients. ${ }^{26}$ Most notably, the ethnic division proxy becomes insignificant (and remains insignificant after the inclusion of other explanatory variables). It appears that ethnic diversity is not correlated per se with corruption, but through lower income levels or through other variables correlated to income, such as schooling. A similar effect occurs for the coefficients of the Protestants variable and of natural resources in exports, though these coefficients remain significant. ${ }^{27}$

At the same time, we must emphasize that the inclusion of income as a independent variable runs the risk of creating an endogeneity problem: since corruption, and institutions in general, have been found to affect the growth rate of income, and since institutional quality tends to be stable over time, it is possible that corruption determines income levels rather than the other way around. ${ }^{28}$ A possible strategy for tackling the issue of endogenity is the use of

\footnotetext{
26 The income variable refers to 2001.

27 Indeed, for natural resources there is a large literature on the 'resource curse' and the 'Dutch disease', which have shown the detrimental effect that natural resources have on economic growth (Stevens 2003).

28 On the direction of causality between institutions and income there is a large and growing empirical literature. Most of the authors seem to agree that causality runs from institutions to income, rather than the other way around (e.g. Rodrik et al. 2004; Acemoglu et al. 2001). For an example of an econometric study finding the opposite direction in the causality between growth and institutions, see Chong and Calderon 2000.
} 
instrumental variables. We identify latitude as a good instrumental variable 29 (it is correlated with income at $60 \%$ and we find no ways through which it could directly affect corruption). Latitude has been suggested as a determinant of income by the proponent of theories of geography as a determinant of economic development (e.g. Sachs 2001). Once latitude is inserted among the independent variables, acting as an instrument for income, the coefficients of the other independent variables tend to increase in magnitude and to become more statistically significant (not shown in this paper). Most notably, the variables describing democracy, newspapers circulation and political instability (see below) increase their coefficients. But, equally important, we do not find any of the variables that we found not to be significant in the main analysis to become significant when using the instrument. . $^{30,31}$

While the income endogeneity issue can be taken care of via the use of instrumental variables, we prefer an alternative solution, using a lagged income variable. The reason is that we are not so much interested in the coefficient of income itself, which can be biased due to endogeneity, but we are more interested in the use of income as a control variable. Our aim is to filter out that part of the coefficients for other independent variables that may go through income. We thus use income to improve the robustness of our estimates. Summing up, choosing to present results from the WLS regressions we favor type I errors, but the difference with the results with the instrumental variables would not alter substantially our conclusions.

One of the main findings of Treisman (2000) that contradicts existing literature (e.g. Fisman and Gatti 2002) is the trend for federalism to increase corruption. We use as a proxy of power decentralization the share of expenses that are delegated to local authorities as compared to the central government. ${ }^{32}$ Once we include such a proxy in our regressions, we do not find that decentralization has a positive correlation with corruption. On the contrary, we find the proxy for decentralization to have a negative correlation with corruption, though the coefficient is not statistically significant. We interpret this result as a

\footnotetext{
29 A good instrumental variable must be highly correlated with the variable to be instrumented and should not have additional explanatory power.

30 The only exception is contemporary democracy that becomes significant. In the analysis below, we prefer to use and discuss the measure of medium-term persistence of democracy, because it is significant even with the inclusion of income. In any case, the null hypothesis of exogeneity is not rejected by the Hausman test.

31 A note of caution is needed when we analyze the results with the instrumental variable, because theories that link geographical factors to institutions and through them to income levels have been developed (Hall and Jones 1999; Acemoglu et al. 2001). If these theories are correct, latitude could be used as an instrumental variable for corruption as well, and the interpretation of the 2-stage results would become problematic. For our own dataset, we checked whether latitude could be used as an instrument for corruption in a regression on income and found that latitude would not be a valid instrument, because it retained explanatory power when added to corruption in the regression.

32 Unfortunately, our proxy for decentralization is available just for a small sample of countries. Once more statistics on government finance, uniform across countries, are available a more reliable empirical test of the link between decentralization and corruption will be possible.
} 
weak suggestion that federalism does not increase corruption. ${ }^{33}$ One reason for the difference between our findings and Treisman (2000) finding can lay in the fact that Treisman uses a dummy variable to characterize a state as federalist or centralist based on an incomplete list of federal countries in Elazar 1995. Apart from its incompleteness, another problem of this list is that an officially federalist country may in fact be overly centralized, where Mexico is a case in point. ${ }^{34}$ The evidence is less than conclusive, as it is based on a sample of only 42 countries, but deserves to be mentioned as a matter that merits further inquiry (see also Arikan 2004). In the remaining regressions, the decentralization proxy is omitted in order to keep a larger sample of countries.

The inclusion of a contemporary democracy variable in regression (4) does not produce a significant coefficient. This result is different when compared to most of the literature that specifically tests the democracy hypothesis. We conjecture that the reason for this is that most other models work with less control variables (e.g. Hill 2003; Chowdhury 2004) or with smaller samples (Sandholtz et al. 2000) leading to omitted variable bias. In the table, we introduced a proxy for democracy from the Polity IV dataset (measuring democratic levels of institutions as judged by a panel of experts, averaged over the period 1994-2003). As an alternative (not reported in the Table), we used a proxy from the Polyarchy dataset (measuring participation and competition at the elections through a mathematical interpretation of elections results, also for the period 1994-2003). None of the two democracy's proxies seem to affect the corruption level, but only when we exclude the income variable. Thus, it is possible that there is an indirect effect of democracy levels through income on corruption (see Barro 1996; and the literature that has sprung from his work).

Constructing a dummy variable for stable democracies ${ }^{35}$ (where there are no coups, or other major interruptions of the nature of the government, and the country has democratic institutions in terms both of elections and of administration of power), we find that a long exposition to democracy has a mitigating effect on corruption. Thus, a '30 years of uninterrupted democracy' variable [as reported in regression (6)] is significant at $5 \%$. The absolute size and the statistical significance of the coefficient increases if more decades are included in the dummy. A dummy characterizing countries that experienced 50 years of uninterrupted democracy is significant at $1 \%$. Our finding thereby presents

\footnotetext{
33 To be sure, we also included, as a proxy of the size of the country, the natural logarithm of the population (as in Fisman and Gatti 2002), to account for the fact that countries with different size may have different 'natural' centralization levels. Conform with previous literature, we did not find the variable to be significant or to affect the coefficient of the decentralization variable.

34 In the United States of Mexico, central government spending exceeds the States and the local governments spending together by more than three times. While the Mexican constitution is of federal nature, political power is centralised in the country's capital. 'For most of the seven decades of rule by the Institutional Revolutionary Party (PRI), Mexico was a highly centralised one-party polity. State governors, and even many mayors, were named by the president and answered to him, even if they were duly elected, by fraud if need be', see 'Mexico's truncated moves towards real federalism', March 27th 2003, From The Economist print edition.

35 We set the cut off point at the level of seven on a 0-10 scale of democracy in the Polity IV variable.
} 
an intermediate position where it is not contemporary levels of democracy that are significant predictor of corruption (e.g. Chowdhury 2004), but it is also unnecessary to have 45 years of uninterrupted democracy as in Treisman (2000). According to our estimates, more than 10, but less then 45 years of a persistently democratic regime is sufficient to produce a significant dividend in terms of corruption reduction.

An issue related to democracy that attracted some attention recently is the role of press. We include the variable of newspapers circulation in order to catch the possible effect of that the mass medias can play in reducing corruption. Our empirical finding [regression (7)] supports the hypothesis that countries where access to press is more wide spread will have less corruption. ${ }^{36}$

There are finally the theories related to government policies. Thus, we have included in regressions (8) and (9) an index of government intervention in the economy, a proxy of political instability, and a measure of wages in the public sector. The proxy for government intervention in the economy is computed using government consumption as a percentage of the economy, government ownership of businesses and industries, the share of government revenues from state-owned enterprises, and government ownership of property and economic output produced by the government. While we do not find support for the hypothesis that government intervention is associated with corruption, we are cautious as to its interpretation, because an increase in government activities in the economy can refer to both restrictions that provide more opportunities for rents' appropriation, but it can also refer to higher expenditures in education and health, or in public goods in general. These in turn could be channels through which corruption is diminished.

The political instability is obtained averaging the number of "veto players" changes in the political system in each year. The variable we employ is a proxy of political instability that recognizing the diffuse nature of political power in most countries. It computes the total number of veto players in the political structure and then evaluates the number of them that have changed in a year. The results show that political instability seems to be significantly associated with corruption, thus the shortening of the time horizons of politicians would affect corruption levels. While evidence of this relation is tentative and would deserve further testing, we highlight that this result is mostly due to the increase in sample size and the use of a better proxy for political instability as compared to Treisman's work. ${ }^{37}$

Finally, we add government wage as an independent variable. We add this government-related variable last, because of the fact that the variable is available only for a reduced sample (72 countries). The government wage is obtained

\footnotetext{
36 We also checked whether the interaction term between contemporary democracy and newspapers circulation would be significant, controlling whether a free press together with a democratic regime would have a special effect on corruption levels. In our regressions the interaction term was not significant.

37 Treisman employed a variable that simply stated the number of government leaders changes in each year.
} 
by dividing the average wage in the public sector by GDP per capita. The government wage variable has the predicted negative sign, but is significant only at $12 \%$. Since the sample is relatively small, it is possible that with more data on government salaries and a better proxy for the opportunity costs faced by civil servants if they loose their jobs it would be possible to get a significant coefficient. ${ }^{38}$

As a robustness check of our findings, we have run ordinary least squares regressions with identical specifications, only with the Transparency International's corruption perception index for 2004 as a dependent variable. ${ }^{39} \mathrm{We}$ find similar results, but with a slightly smaller dataset and decreased significance of most coefficients. ${ }^{40}$ There are two differences in the estimates. First, the share of fuels and minerals in exports tends to become statistically insignificant in most regressions, and second, the import share in GDP is significant when income is excluded as an independent variable. Subsequently, we used the corruption perception index of the World Bank for the years 1996, 1998, 2000, and 2002 instead of 2004 as a dependent variable to check our results, with the independent variables also referring to earlier years than in our main analysis. Again, results are similar with two exceptions. Fuels and minerals in exports tend to be slightly more significant in some regressions, and newspapers circulation tends to be slightly less significant in some (other) regressions.

\section{Discussion and conclusions}

Our exercise contributes to the existing literature as it questions some central findings of previous econometric studies. Most notably, for some historical characteristics of a country that have been said to be a cause of corruption, we do not find support. In our statistical analysis we do not find that the common law system or a past as a British colony (negatively) predict corruption. Furthermore, we do not find any association between decentralization and corruption. Moreover, the link between ethnolinguistic fractionalization and corruption is diminished and becomes insignificant once income is included in the regressions. We do find systematic evidence that supports cultural theories of the causes of corruption, in that the presence of Protestants in the population is found to be associated with lower corruption. We also find that richer countries are less corrupt. As mentioned above, caution is needed as there could be reverse causality from institutional quality to income, though the result is upheld using an

\footnotetext{
38 A better proxy would be the ratio of civil servants pay to service or manufacturing salaries (that are not influenced by the share of population employed in the agricultural sector). Van Rijckeghem and Weder (2001) use the ratio of government wages to manufacturing wages and find it to be a significant determinant of corruption levels. Their data sample, though, is limited to 31 countries and data limitations do not allow us to follow their data.

39 The estimates if Transparency International's margins of error have been shown to be biased (Kaufmann et al.2005), therefore we preferred the ordinary least squares, as a regression technique, rather than the weighted least squares technique.

40 The sample size ranges between 98 and 67 countries.
} 
instrumental variable. Another finding shows that a long exposure (30 years) to uninterrupted democracy is associated with lower corruption, that political instability tends to raise corruption, and that the diffusion of newspapers is associated with lower corruption levels. Finally, we also find some evidence of an association of higher wages in the public sector with lower corruption.

What distinguishes our study from previous econometric works is, apart for some different variable choices, a larger sample and we suggest that the most notable differences with earlier studies can be traced to the inclusion of new countries in the present study. We are aware of the limitations on the interpretation of econometric results. Econometrics has a bias towards theories that can easily be quantified. Case studies and more theoretical studies can act as a necessary complement of this type of work (e.g. Johnston 2005). For future research, we hope to follow two approaches. First, we want to investigate determinants of corruption that are amenable to policy changes. This search can be enhanced through the use of econometric analyses that identify the sources of corruption at the micro level (e.g. Fisman and Miguel 2006; Miller 2006; Reinikka and Svensson 2006). Second, we consider another relevant challenge to be the collection of sufficient data for a panel data approach over a number of decades. The combined cross-country-or cross-region-and intertemporal analyses possible with panel data can be a key to finding other sources of corruption.

Acknowledgments The research has been funded by the Dutch National Science Foundation (NWO) under contract no. 016.005.040.

\section{Appendix}

Table 2 Descriptive statistics

\begin{tabular}{lcccrr}
\hline Variables & Obs & Mean & Std. Dev. & Min & Max \\
\hline Corruption & 106 & 0.00 & 1.07 & -2.47 & 1.55 \\
Protestants & 106 & 0.13 & 0.21 & 0.00 & 0.98 \\
Ethnolinguistic fractionalization & 106 & 0.33 & 0.30 & 0.00 & 0.89 \\
Fuels and minerals & 106 & 0.20 & 0.26 & 0.00 & 0.97 \\
Imports & 105 & 0.39 & 0.20 & 0.09 & 1.34 \\
Income [ln(GDP) per capita] & 106 & 8.38 & 1.19 & 6.20 & 10.39 \\
Decentralization & 42 & 0.33 & 0.28 & 0.02 & 1.33 \\
Contemporary democracy & 104 & 0.72 & 0.29 & 0.05 & 1.00 \\
Newspapers circulation & 104 & 1.10 & 1.48 & 0.00 & 7.60 \\
Government intervention & 106 & 2.94 & 0.75 & 1.50 & 4.70 \\
Instability & 105 & 0.14 & 0.10 & 0.00 & 0.41 \\
Government wage & 73 & 3.25 & 2.47 & 0.60 & 11.80 \\
\hline
\end{tabular}

Corruption is the perceived corruption index 2004, from the World Bank (see Kaufmann et al. 2005); Protestants is the share of Protestants in the population, Ethnolinguistic fractionalization is a average of five different indexes based on linguistic groups (for the last two variables see La Porta et al. 1999); Fuels and minerals equals to the share of fuels and minerals on exports, 
averaged over 1993-2002, Income in the natural logarithm of GDP per capita in 2001, (the last two variables are from the World Development Indicators 2004); Decentralization is the expenses of state and local government divided by the central government averaged over 1993-2002 (from the 'Government Finance Statistics 2004' of the International Monetary Fund); Contemporary Democracy is the average of the institutional democracy score for the years 1994-2003 from the Polity IV dataset (see Jaggers et al.); Newspapers Circulation is daily newspapers circulation for 10 people; Imports is a measure of the openness of the economy and equals to the share of imports over GDP, averaged over 1993-2002 (the last two variables are from the World Development Indicators 2004); Government Intervention is an index for 2004 of the influence of government on the economy based on government consumption as a percentage of the economy, government ownership of businesses and industries, the share of government revenues from state-owned enterprises, and government ownership of property and economic output produced by the government (from The Index of Economic Freedom 2005); Instability is the percentage of veto players that changed every year, averaged for 1991-2000 (see Beck et al. 2000); Government Wage is the average government wage as a multiple of GDP per capita (from Schiavo-Campo 1998); British Colony is the dummy variable for countries that have been under British control (from Treisman 2000 augmented with information from Flags of the World Website http://flagspot.net/flags/gbcolon.html); Common Law is the dummy variable for countries that adopted the common law system in their commerical code (from La Porta et al. 1999).

\section{References}

Acemoglu D, Verdier T (2000) The choice between market failures and corruption. Am Econ Rev 90(1):194-211

Acemoglu D, Johnson S, Robinson JA (2001) The colonial origins of comparative development: an empirical investigation. Am Econ Rev 91(5):1369-1401

Arikan GG (2004) Fiscal decentralization: a remedy for corruption? Int Tax Publ Fin 11(2):175-195

Barro R (1996) Democracy and growth. J Econ Growth 1(1):1-27

Beck T, Clarke G, Groff A et al. (2000) New tools and new tests in comparative political economy: the database of political institutions. The World Bank, Washington DC

Becker GS (1968) Crime and punishment-economic approach. J Polit Econ 76(2):169-217

Bohara AK, Mitchell NJ, Mittendorff CF (2004) Compound democracy and the control of corruption: a cross-country investigation. Policy Stud J 32(4):481-499

Brunetti A, Weder B (2003) A free press is bad news for corruption. J Public Econ 87(7-8):18011824

Chafuen AA, Guzmán E (1999) Economic freedom and corruption. In: O'Driscoll GP, Holmes KR, Kirkpatrick M, 2000 index of economic freedom. Heritage Foundation, Washington DC

Chong A, Calderon C (2000) Causality and feedback between institutional measures and economic growth. Econ Polit 12(1):69-81

Chowdhury SK (2004) The effect of democracy and press freedom on corruption: an empirical test. Econ Lett 85(1):93-101

Elazar DJ (1995) From statism to federalism - a paradigm shift. Publius J Feder 25(2):5-18

Fisman R, Miguel E (2006) Cultures of corruption: evidence from diplomatic parking tickets. NBER working paper. National Bureau of Economic Research

Fisman R, Gatti R (2002) Decentralization and corruption: evidence across countries. J Publ Econ 83(3):325-345 
Glaeser EL, Shleifer A (2002) Legal origins. Q J Econ 117(4):1193-1229

Hall RE, Jones CI (1999) Why do some countries produce so much more output per worker than others? Quart J Econ 114(1):83-116

Hill KQ (2003) Democratization and corruption-systematic evidence from the American states. Am Polit Res 31(6):613-631

Jaggers K, Gurr TR (1995) Tracking democracy 3rd-wave with the polity-III data. J Peace Res 32(4):469-482

Jain AK (2001) Corruption: a review. J Econ Surv 15(1):71-121

Johnston M (2005) Syndromes of corruption: wealth, power, and democracy. Cambridge University Press, Cambridge

Kaufmann D, Kraay A, Mastruzzi M (2005) Governance matters IV: governance indicators for 1996-2004. World bank policy research working paper series

Knack S, Azfar O (2003) Trade intensity, country size and corruption. Econ Govern 4(1):1-18

La Porta R, Lopez-De-Silanes F, Shleifer A et al. (1999) The quality of government. J Law Econ Organ 15(1):222-279

Lambsdorff JG (1999) Corruption in empirical research-a review. Transparency International, Berlin

Lambsdorff JG (2004) Framework Document 2004: a background paper to the 2004 Corruption Perceptions Index. Transparency International and Passau University

Landes D (1999) The wealth and poverty of nations: why some are so rich and some so poor. W. W. Norton \& Company, New York

Leite C, Weidmann J (1999) Does mother nature corrupt? Natural resources, corruption, and economic growth. IMF Working Paper. International Monetary Fund. Washington DC

Macaulay TB (1843/2001) Critical and historical essays: vol 1. The World Wide School, Seattle

Mauro P (1995) Corruption and growth. Q J Econ 110(3):681-712

Miller WL (2006) Corruption and corruptibility. World Dev 34(2):371-380

Reinikka R, Svensson J (2006) Using micro-surveys to measure and explain corruption. World Dev 34(2):359-370

Rodrik D, Subramanian A, Trebbi F (2004) Institutions rule: the primacy of institutions over geography and integration in economic development. J Econ Growth 9(2):131-165

Rose-Ackerman S (1999) Corruption and government: causes, consequences, and reform. Cambridge University Press, Cambridge

Sachs JD (2001) Tropical underdevelopment. NBER Working Paper

Sandholtz W, Koetzle W (2000) Accounting for corruption: economic structure, democracy, and trade. Int Stud Q 44(1):31-50

Schiavo-Campo S (1998) Government employment and pay: the global and regional evidence. Publ Admin Dev 18:457-478

Stevens P (2003) Resource impact - curse or blessing? A literature review. J Energy Lit 9(1):3-42

Sung H -E (2004) Democracy and political corruption: a cross-national comparison. Crime, Law Soc Change 41:179-194

Transparency International (2004) Global corruption barometer. Transparency International, Berlin

Treisman D (2000) The causes of corruption: a cross-national study. J Publ Econ 76(3):399-457

Van Rijckeghem C, Weder B (2001) Bureaucratic corruption and the rate of temptation: do wages in the civil service affect corruption, and by how much? J Dev Econ 65(2):307-331

Williams R (1999) New concepts for old? Third World Q 20(3):503-513 